\title{
PRESENCIAS Y SILENCIOS. BIOGRAFÍAS DE MÉDICOS EN EL ANTIGUO RÉGIMEN
}

\author{
José Pardo Tomás
}

Científico titular, Institució Milà i Fontanals, CSIC, Barcelona

\section{Àlvar Martínez Vidal}

Profesor titular de Historia de la Ciencia, Universitat Autònoma de Barcelona

\section{RESUMEN}

El artículo presenta las experiencias y reflexiones suscitadas durante y después de la elaboración de una serie de biografías - tanto colectivas como individuales - de médicos cortesanos españoles en los siglos XVII y XVIII. Se trata de un proyecto de investigación desarrollado en los últimos doce años que culmina ahora, en parte, con la publicación del libro El médico en la palestra.

PALABRAS CLAVE: Biografías, prosopografía, médicos cortesanos, antiguo Régimen, España, siglos XVII-XVIII.

\section{SUMMARY}

The article presents the experiences and reflexions arisen from the elaboration of physicians' biographies -individual as well as collective - in the Spanish Court during the Seventeenth and Eighteenth-centuries. They are part of a twelve years research project, which culminates with the publication of the book El médico en la palestra.

KEY WORDS: Biography, prosopography, court physician, old Regime, Spain, 17th-18th centuries.

\section{INTRODUCCIÓN}

Thomas Söderqvist ha sido, sin duda, en estos últimos diez años, el historiador de la medicina que más ha escrito acerca de la intersección entre nues- 
tra disciplina y el género biográfico ${ }^{1}$. En el meollo de sus reflexiones se encuentra la afirmación clara y tajante de la independencia radical del género biográfico y la defensa de su propia soberanía, basada en una tradición incomparablemente más larga que la de la historia de la medicina, en su capacidad para establecer sus propias reglas del juego y en una definición de usos e intenciones que ha ido, que va y que irá, mucho más allá de lo que la práctica historiográfica ha hecho con él ${ }^{2}$. La valoración de Söderqvist acerca de lo que los historiadores de la medicina y de la ciencia han reflexionado sobre el género biográfico no es especialmente benigna: lo que hasta ahora se ha cosechado han sido, según sus propias palabras, «acercamientos anecdóticos, fragmentarios, ensayísticos e idiosincráticos» $»^{3}$.

1 Lo último, aún inédito en el momento de presentar los originales de este artículo (diciembre 2004), es: SöDERQVIST, T. (en prensa), «Introduction: The Poetics of Biography and the Historiography of Science», en: T. Söderqvist (ed.), The Poetics of Biography in Science, Technology and Medicine, Aldershot: Ashgate, [1-40]. Hemos de agradecer al autor la rapidez y generosidad con que atendió a nuestra petición del texto mecanoscrito y el permiso que nos ha concedido para citarlo aun antes de su publicación. Aprovechando la gentileza de Söderqvist, hemos tenido también acceso a otros dos textos suyos, originalmente dos conferencias, que nos han sido de gran utilidad: SöDERQVIST, T. (2003a), «Lives of Scientists as Sources for Ethical Reflection, or: Why Should We Remember a Life Scientist?», conferencia del The Sir William Paton Memorial impartida en el Wellcome Trust Centre for the History of Medicine de Londres, en abril del 2003; y SöDERQVIST, T. (2003b), "Why are there so few scholarly biographies in the history of medicine and public health?», conferencia preliminar en el VII Congreso de la European Association for the History of Medicine and Health, celebrado en Oslo, en septiembre de 2003. Además, por supuesto, de su trabajo anterior SöDERQVIST, T. (1996), «Existential projects and existential choice in science: science biography as an edifiyng genre» en: M. Shortland; R. Yeo (eds.), Telling Lives in Science, Baltimore-London, Johns Hopkins University Press, 45-84; y de la versión en inglés de la biografía del inmunólogo danés Niels Jerne: SöDERQVIST, T. (2003c), Science as Autobiography: The Troubled Life of Niels Jerne, New Haven-London, Yale University Press.

2 Valga como ejemplo el mundo de la llamada «biografía literaria», ese «arte necrofílico que goza de tan buena salud», en palabras de Martin Stannard, y que constituye toda una especialidad académica, además de editorial y periodística, especialmente en el mundo anglosajón. Puede valer como útil panorama, entre otras cosas, el volumen editado por SALWAK, D. (1996), The Literary Biography. Problems and Solutions, Iowa City, University of Iowa Press, dedicado a exponer algunos de los «problemas y soluciones» en una veintena de capítulos de otros tantos especialistas, entre ellos el citado Martin Stannard, Justin Kaplan, John Halperin, o Antony Alpers. Resulta interesante anotar que cuando los especialistas en la biografía literaria hablan de «biografía histórica» parecen presentar un desenfoque similar al que los historiadores presentamos cuando tratamos de aproximarnos a lo indudablemente «literario» de nuestra labor como biógrafos.

3 La cita procede de SöDERQvist, T. (en prensa), p. 10. 
Debemos, pues, admitir de partida que estas reflexiones sobre nuestra experiencia como biógrafos no pueden ser sino también anecdóticas, fragmentarias, ensayísticas e idiosincráticas, por lo que no aspiran a modificar el diagnóstico de Söderqvist. Por otra parte, el hecho de que la convocatoria de la reunión «Biografías médicas, una reflexión historiográfica» de la que emana este artículo se hizo en un marco estrictamente disciplinar (por mucho que en él se abogue siempre por encuentros interdisciplinares e incluso se diera un cierto margen a ello en el programa), parece exigir una cierta manera de tratar este asunto en una revista de la especialidad.

No pretendemos aquí ir más allá de la exposición, todo lo más ordenada que podamos, de nuestras experiencias de más de diez años en la elaboración de diversas modalidades de «aproximación biográfica». Por fortuna o por desgracia, éstas no nacieron de una llamada exterior con intenciones conmemorativas, de manera que no son estrictamente pertinentes aquí los esfuerzos explicativos y autoreflexivos de otros historiadores de la ciencia que han tenido que lidiar con celebraciones, centenarios y otros tributos a la memoria de grandes figuras, tratando de legitimar sus biografías y ofreciendo, de paso, interesantísimas consideraciones sobre los usos del género desde la historia de la ciencia, así como valiosos análisis de otras prácticas conmemorativas ${ }^{4}$. Al contrario, conviene comenzar señalando que nuestras aproximaciones se realizaron en el marco de una línea de investigación sobre los médicos novatores en la corte española de finales del siglo XVII y principios del siglo XVIII.

Esta línea, por el momento, se ha materializado en diversos proyectos parciales, en la publicación de una docena de trabajos firmados a dos nombres ${ }^{5} \mathrm{y}$

4 El lector interesado puede acudir a BENSAUDE-VINCENT, B. (1996), «Between History and Memory: Centennial and Bicentennial Images of Lavoisier», Isis, 87, 481-499; así como a los reunidos en el monográfico editado por PNINA G.; ABIR-AM; CLARK, A.E. (1999), «Commemorative Practices in Science. Historical Perspectives on the Politics of Collective Memory», Osiris, 14; también a JoRDANOVA, L. (2000), "Remembrance of science past», British Journal for the History of Science, 33, 387-406; y a FARA, P. (2000), «Isaac Newton lived here: sites of memory and scientific heritage», British Journal for the History of Science, 33, 407-426.

5 Entre otros: MARTínez VidAl, À.; PARdo TOMÁs, J. (1995), «In tenebris adhuc versantes. La respuesta de los novatores españoles a la invectiva de Pierre Régis», Dynamis, 15, 301-340; PARdo TomÁs, J.; MARTínez VidAL, À. (1996), «El Tribunal del Protomedicato y los médicos reales (1665-1724): entre la gracia real y la carrera profesional», Dynamis, 16, 59-89; MARTíneZ VIDAL, À.; PARDO TOMÁS, J. (1997), «Los orígenes del teatro anatómico de Madrid (1689-1728)», Asclepio, 49, 5-38; PARdo TomÁs, J.; MARTínez Vidal, À. (2002), «Las consultas y juntas de médicos como escenarios de controversia científica y práctica 
en la elaboración de una biografía que, aunque firmada por uno de nosotros, es fruto de la reflexión y el diálogo continuo entre ambos ${ }^{6}$. En el horizonte inicial del proyecto, sin embargo, ni siquiera se contemplaba recurrir al relato biográfico para tratar un tema que entonces, hace doce años, se planteaba en términos perfectamente compatibles con la interpretación de López Piñero elaborada entre 1962 (fecha de aparición del primer artículo sobre Cabriada) ${ }^{7}$ y 1979 (fecha de publicación de Ciencia y técnica), hace ahora ya un cuarto de siglo ${ }^{8}$. Dicha interpretación es de todos conocida, pero vamos a tratar de sintetizarla en pocas palabras.

La introducción de la ciencia moderna en España fue un proceso iniciado por el movimiento novator del último tercio del siglo XVII para tratar de superar la ausencia española del punto de partida de la revolución científica. Dicho movimiento se desarrolló a partir de los círculos intelectuales de ciudades como Valencia, Zaragoza o Sevilla y presentó vicisitudes algo diversas en los dos campos científicos principales: el físicomatemático y el médico. Los novatores, tras la denuncia abierta del atraso español, trataron de difundir las nuevas teorías científicas vigentes en el resto de Europa, no sin hallar fuertes resistencias por parte del tradicionalismo, aún sólidamente instalado en los ámbitos eclesiástico y académico. Entre los lugares alcanzados por el impulso del movimiento novator figuraba la corte madrileña, donde la dialéctica entre tradición y renovación se plasmó en diferentes polémicas, como la surgida a raíz de la publicación del texto considerado el manifiesto del movimiento renovador, la Carta filosófica médico chymica de Juan de Cabriada (Madrid, 1687).

Nuestro acercamiento al ambiente médico cortesano de los reinados de Carlos II y Felipe V partía, inicialmente, de este marco. Se planteaba, por un lado, ahondar en la trayectoria intelectual, institucional y profesional de los

médica en la época de los novatores (1687-1725)», Dynamis, 22, 303-325; y MARTíNEZ VIDAL, À.; PARDO TOMÁs, J. (2003), «Un siglo de controversias: la medicina española de los novatores a la Ilustración», en: J. L. Barona; J. Moscoso; J. Pimentel (eds.), La Ilustración y las ciencias. Para una historia de la objetividad. València, Universitat de València-Biblioteca Valenciana, 107-135.

6 Pardo Tomás, J. (2004), El médico en la palestra. Diego Mateo Zapata (1664-1745) y la ciencia moderna en España, Salamanca, Junta de Castilla y León.

7 LÓPEZ PIÑERO, J.M. (1962), «Juan de Cabriada y las primeras etapas de la iatroquímica y de la medicina moderna en España», Cuadernos de Historia de la Medicina Española, 2, 129-154.

8 LÓPez PIÑERo, J.M. (1979), Ciencia y técnica en la sociedad española de los siglos XVI y XVII, Barcelona, Labor. 
autores que habían participado en las controversias científicas publicando una numerosa serie de textos polémicos; por otro lado, prolongar el análisis de esas fuentes hasta las primeras décadas del siglo XVIII, tratando en ambos casos de establecer las relaciones personales e intelectuales del ambiente cortesano madrileño con otros círculos científicos hispanos e italianos.

\section{NuEVAS FUENTES, NUEVAS PREGUNTAS: DE LAS CARRERAS DE MÉDICOS CORTESANOS A LAS BIOGRAFÍAS MÉDICAS}

Durante la búsqueda de información sobre los autores de esas obras, nos topamos con dos series de fuentes que hasta ese momento no habían sido consideradas y que acabaron por modificar nuestros objetivos iniciales. A la postre, fueron estas nuevas fuentes las que abrieron otras vías de agua en el planteamiento inicial de nuestro proyecto y acabaron por transformar también el marco interpretativo del que partimos. Resulta evidente que no se trató simplemente del acceso a nuevas fuentes, pero es necesario admitir que sin ellas quizá tampoco nuestra manera de hacer hubiera tomado el derrotero que tomó hasta desembocar, entre otras cosas, en la decisión de escribir una biografía.

Expondremos, brevemente, qué tipo de fuentes se consultaron. En primer lugar, una serie documental de expedientes personales en el Archivo General de Palacio, de Madrid. En segundo lugar, una serie documental en la sección de Inquisición del Archivo Histórico Nacional, fruto de los procesos por criptojudaísmo que el Santo Oficio abrió contra algunos de los médicos cortesanos a partir de 1720 .

La primera de estas series permitió conocer la trayectoria institucional y profesional de más de un centenar de médicos que, de una u otra forma, tuvieron relación con las instituciones cortesanas durante el medio siglo que va de 1680 a 1730 . Es importante señalar, para los fines que nos ocupan, que la mayoría de estos médicos eran completamente desconocidos, debido sobre todo a que no eran autores de obras impresas, lo que los había hecho prácticamente invisibles para los historiadores de la medicina. Su silenciosa presencia, sin embargo, obligaba a enfocar las luces hacia ellos. Allí estaban sus peticiones de cargos, sus exposiciones de méritos, sus trayectorias universitarias, profesionales y asistenciales, sus cargos y nombramientos y, en ocasiones, sus deudas, sus protestas y sus reclamaciones de honores, ascensos u otras formas de reconocimiento social. Parecía lógico, por tanto, tratar de reconstruir las carreras universitarias, profesionales y cortesanas de ese centenar de médicos para obtener un perfil prosopográfico del médico cortesano de esa época y su evolución. Aquí es necesario reconocer que el análisis pro- 
sopográfico se apoyó también en el cruce de información con la base de datos del proyecto PAPE, elaborada en el marco de una investigación cuya sede principal se halla en la Maison des Pays Ibériques, del CNRS francés y la Universidad de Burdeos III «Michel de Montaigne», bajo la dirección de Jean-Pierre Dedieu ${ }^{9}$.

Los resultados del análisis prosopográfico permitieron modificar en más de un sentido nuestro punto de vista y, por qué no decirlo, cambiar algunas de las preguntas iniciales de nuestra indagación. La lectura de los textos médicos impresos de la época hecha a la luz de esta otra documentación obligaba a replantearse las preguntas heredadas. Quizá había que partir de otra interpretación.

Nuestro objetivo no podía seguir siendo confirmar, modificar o descartar la definición ideológica de los autores en una clasificación elaborada según las diferentes posturas frente a teorías consideradas vectores de la llamada ciencia moderna (circulación de la sangre, iatroquímica versus iatromecánica, antiaristotelismo, atomismo, etc.) y prácticas científicas consideradas como síntomas de filiación moderna (disección anatómica, uso del microscopio, elaboración de medicamentos químicos, observación y experimentación clínicas).

Nos hallábamos frente a un numeroso colectivo de médicos con trayectorias diversas que les llevaron a estar relativamente bien situados en los diferentes estratos de una sociedad cortesana característica del Antiguo Régimen, uno de cuyos pilares fundamentales era la gracia real, entendiendo por ello la atribución exclusiva al monarca absoluto de conceder mercedes y privilegios. En nuestra interpretación, había que introducir nuevas variables sobre el papel jugado por las controversias públicas en materias científicas y por las decisiones de crear determinadas instituciones (como la cátedra de anatomía del Hospital General de Madrid, o la Regia Sociedad de Medicina y Otras Ciencias de Sevilla). Al poder reconstruir en parte las carreras de novatores y tradicionalistas, así como de otros hasta ahora testigos mudos de su lucha, se veían desde otra perspectiva las diversas opciones profesionales que se les presentaban, los motivos que les llevaron a participar en las controversias públicas e incluso el modo de hacerlo, de elaborar y argumentar sus posturas en los textos. Parecía lógico dirigir la mirada a esos territorios menos explorados, sin eludir que nuevas preguntas permitían desembarazarse del requerimiento de dar respuesta a otras que tenían mucho más que ver con la herencia

9 Castellano, J.L. (ed.) (1996), Sociedad, administración y poder en la España del Antiguo Régimen. Hacia una nueva historia institucional. I Simposium Internacional del Grupo P.A.P.E., Granada, Universidad de Granada; DeDIEU, J.P. (2000), «Un instrumento para la historia social: la base de datos Ozanam», Cuadernos de Historia Moderna, 24, 11-31. 
de la polémica de la ciencia española que con las cuestiones que llamaban la atención de la historiografía de estos últimos años: el papel del patronazgo nobiliario y de la gracia real en el desarrollo de las carreras, el papel del público lector en la producción de obras polémicas, la evolución de la retórica de las controversias científicas, los mecanismos de legitimación de saberes y prácticas científicas nuevas o nuevamente formuladas, la apropiación de ideas y teorías científicas en contextos distintos de donde se elaboraron, la articulación de canales de comunicación centro-periferia en el marco de la llamada República de las Letras, etc.

Podríamos extendernos más respecto de estos asuntos, pero eso nos distraería de nuestro propósito aquí y ahora, que es el de señalar que la aproximación biográfica a unos personajes hasta entonces silenciosos desde el punto de vista histórico, fue determinante a la hora de marcar la evolución de nuestro proyecto. Obviamente, se trataba hasta aquí de una aproximación biográfica claramente instrumental, impuesta por las fuentes y que no se plasmó en una narración biográfica dentro de los requerimientos del género, sino más bien en una utilización «a la carta» de las técnicas prosopográficas, que, como es bien sabido, no son ni mucho menos lo mismo, aunque compartan algunas maneras de hacer.

Otra consecuencia del análisis prosopográfico es casi inherente al método, aunque se trate de una consecuencia, si se quiere, con efectos solamente de puertas para dentro de la cocina del investigador. Siempre que se trabaja en una prosopografía sobreviene la sensación de malestar e incomodidad al reducir la vida de un individuo a una ficha escueta, esquematizada en media docena de criterios y con la finalidad última de integrarlo en un mero porcentaje. La mayor parte de las veces, la precariedad o parquedad de las fuentes sirven de excusa para rechazar el malestar o aceptarlo como inevitable. En nuestro caso, sin embargo, las fuentes no sólo no sirvieron de excusa, sino que exigieron hacer frente con nuevos bríos al «malestar de la prosopografía». Fue el segundo tipo de fuentes al que hacíamos referencia al principio lo que cambió las cosas en este sentido.

Porque la segunda serie documental aportó una ingente documentación referida a médicos cortesanos, como Francisco de la Cruz, Diego Mateo Zapata y Juan Muñoz y Peralta, que fueron víctimas de la última gran persecución contra los conversos llevada a cabo por la Inquisición, entre la segunda y la tercera década del siglo XVIII. En la sección Inquisición del Archivo Histórico Nacional se ha conservado la documentación relativa al secuestro de sus bienes, donde se encontraban sus escritos personales, incluida la correspondencia, y la relación de los libros hallados en sus bibliotecas. 
Zapata y Peralta son conocidos gracias, entre otras cosas, a su condición de autores de obra impresa ${ }^{10}$. Sin embargo, el caso del mencionado Cruz, que fue médico del Hospital General y médico de familia de la Casa Borgoña, resulta muy interesante a pesar de su anonimato, ya que la documentación consultada ofrece en sus más mínimos detalles la carrera de un médico cortesano, con sus intereses intelectuales y profesionales, sus lecturas, sus pacientes, sus servidumbres, las redes clientelares con sus protectores y protegidos, etc. El interés de Cruz reside, pues, no tanto en la singularidad de su condición de descendiente de la minoría judeoconversa, como en la representatividad en tanto que exponente del perfil biográfico del médico cortesano.

En suma, ante la variedad y riqueza de la información hallada, resultaba obvio que el acercamiento prosopográfico no era en modo alguno adecuado, ya que no daba respuestas a las nuevas preguntas suscitadas. Se imponía otro tipo de abordaje. El género biográfico parecía, entonces, ser el más idóneo para encontrar respuestas y elaborar un relato histórico más proporcionado a la realidad estudiada. Por este motivo, presentamos nuestras reflexiones en dos encuentros sucesivos (1997 y 1999) ${ }^{11}$. Allí pudimos debatir en torno a las maneras de biografíar a Muñoz y Peralta y a las potencialidades que ofrecía el género biográfico para historiar vidas de médicos cortesanos del Antiguo Régimen. Así, se tomó la decisión de aceptar las exigencias y adoptar las pautas del género biográfico en el caso de los materiales relativos a Diego Mateo Zapata.

10 LÓPEZ PiÑERo, J.M. (1983), «Muñoz y Peralta, Juan»; BALlester, R. (1983), «Zapata, Diego Mateo». Ambos en: J.M. López Piñero et al., Diccionario histórico de la ciencia moderna en España, Barcelona, Península, Vol. II, 94-95 y 445-447, respectivamente. Las dos voces recogen la bibliografía hasta entonces publicada sobre estos autores. Con posterioridad, Alegre, M.E.; ReY, M. (2001), «Terapéutica y poder de entre reinados (1693-1730)». En: J. Castellanos et al. (coords.), Varia histórico-médica, Málaga, Sociedad Española de Historia de la Medicina, 207-216, y LÓPEZ PÉREZ, M.; REY, M. (2001), «La instrumentalización de la espagiria en el proceso de renovación: las polémicas sobre medicamentos químicos». En: F.J. Puerto et al. Los hijos de Hermes. Alquimia y espagiria en la terapéutica española moderna, Madrid, Ediciones Corona Borealis, 279-346.

11 En 1997, fue en el marco del XI Simposio de la Sociedad Española de Historia de la Medicina, Perspectivas actuales de la investigación historicomédica, celebrado en Granada, donde presentamos la ponencia «Fuentes para el estudio de la práctica médica: los papeles privados de Juan Muñoz y Peralta». Dos años más tarde, fue con ocasión de un seminario en la Sociedad Catalana de Historia de la Ciencia, titulado «Un metge a la cort: una reconstrucció biogràfica de Juan Muñoz y Peralta (ca. 1664-1746). Véase la reseña de Alfons Zarzoso en el número 11 de Ictineu (1999), pp. 11-13. 


\section{El PLANTEAMIENTO BIOGRÁFICO EN EL MÉDICO EN LA PALESTRA}

En el discurso biográfico está en juego siempre la tensión entre la singularidad del individuo concreto, con una trayectoria vital única, irrepetible y, desde luego, sujeta al azar, y la representatividad como exponente de una determinada época o de un determinado proceso histórico. El margen estrecho y resbaladizo que equidista de la singularidad y la representatividad es el difícil espacio de la biografía histórica, un espacio transitado por unos y otros, pero más bien desconocido por la mayoría. En el caso concreto de Diego Mateo Zapata, el hecho de haber localizado, en el Archivo Diocesano de Cuenca, las actas de su proceso inquisitorial, hizo surgir el propósito de que uno de nosotros encarara la escritura de su biografía, que, con el título El médico en la palestra, se ha publicado hace unos meses ${ }^{12}$.

Podríamos 'hacer trampa' y presentar nuestro propósito entonces, hace unos años, como el resultado de una meditada decisión a la luz de las interpretaciones historiográficas y de las propuestas metodológicas acerca de la biografía médica. Pero eso, como decíamos, sería hacer trampa. Es cierto que la obra de Harold Cook $^{13}$, así como la aparición en 1996 del volumen colectivo Telling Lives in Science ${ }^{14}$, se situaron en el inicio de la consideración de cómo y por qué se imponía hacer una biografía individual de Zapata.

Pero el alcance de la mayor parte de las propuestas contenidas en ambos libros, así como sus presupuestos historiográficos esenciales, no fueron entendidos de modo cabal hasta después de haber enfrentado el reto de escribir una biografía que se mantuviera a un tiempo dentro de los cánones del género y no demasiado fuera de lo académicamente aceptable en la disciplina.

Lo que sí puede decirse ahora, a raíz de una relectura de aquellos libros y de otros trabajos más recientes, es que ciertamente la biografía es un género en sí mismo y que el paso previo para reintroducirlo en la práctica historiográfica debe ser entender lo que tiene de ajeno a la historia ${ }^{15}$. Söderqvist parece invitar a hacer la biografía médica que mejor convenga a los diversos objetivos, ya pro-

12 PARDO TOMÁs (2004).

13 CoOK, H.J. (1994), Trials of an ordinary doctor. Joannes Groenevelt in SeventeenthCentury London, Baltimore, Johns Hopkins University Press.

14 Shortland, M.; Yeo, R. (eds.) (1996), Telling Lives in Science: Essays on Scientific Biography, Cambridge, Cambridge University Press.

15 Linker, E.O. (en prensa), "'Great Doctors', 'Great Scientists': The Career of Biography in the History of Medicine and Science». In: T. Söderqvist (ed.), The Poetics of Biography in Science, Technology and Medicine, Aldershot, Ashgate [1-20]; SöDERQVIST, T. (2003a); SÖDERQVIST, T. (2003b) y SÖDERQVIST, T. (en prensa). 
vengan del autor o del contexto, a los públicos potenciales, a las características del individuo seleccionado para biografiar y a las fuentes disponibles. Si se hace ateniéndose a las pautas del género, considerando que éstas como es natural han sido y son cambiantes, conscientes de su evolución, de su amplísima tradición y de la complejidad de sus opciones subgenéricas, no se debe atender solamente a la opinión de los colegas académicos (no menos cambiante, por cierto).

Escribir una biografía para convertir la vida de una persona en un «mero síntoma del pasado» era algo contra lo que ya se rebelaba Lytton Strachey, quizá el más apreciado de los biógrafos de la edad de oro del género, en las primeras décadas del siglo pasado. Así lo recordaba Isabel Burdiel en un texto que es, en nuestra opinión, uno de los más sugerentes y originales de los que se han escrito sobre este asunto en los últimos años ${ }^{16}$. No quisiéramos pensar que la biografía contextualista, la que parece gozar de un mayor grado de tolerante benignidad por parte de los historiadores actuales, resulte a la postre sólo una manera más sofisticada de seguir convirtiendo a los individuos en meros síntomas del pasado. De hecho, a la pregunta de por qué escribir una biografía, la respuesta modelada sobre la base de la inevitable cuestión acerca de la representatividad del individuo elegido ha permitido seguir cultivando el género a diversas especies y subespecies de historiadores, entre ellos los de la ciencia; mucho menos, por cierto, a los de la medicina, al decir de Beth Lin$\operatorname{ker}^{17}$, y casi nada a los de la salud pública, según expuso el tan citado Söderqvist en la reunión de la European Association for the History of Medicine and Health celebrada en Oslo, en el año $2003^{18}$. Ciertamente, ello ha conllevado una sobredeterminación del contexto que, en más de una ocasión, ha arruinado por completo la esencia del género biográfico. La parodia de Charles Firth que recordaba Isabel Burdiel en el estudio citado sigue siendo la más gráfica manera de expresarlo. Se trata de la «operación sandwich: un poco de contexto, un poco de vida individual y otra capa de contexto» ${ }^{19}$.

Al menos en su primera parte, los citados consejos de Söderqvist nos sirven como excusa para defender el Zapata que al final se ha construido; pero lo honesto sería decir que en él fue claramente determinante la cuestión de haber tenido acceso a un tipo de fuente bastante insólita para hacer la biografía de un médico de aquella época. En el balbuceo metodológico y de supues-

16 Burdiel, I. (2000), «La dama de blanco. Notas sobre la biografía histórica», en: I. Burdiel; M. Pérez Ledesma (coords.), Liberales, agitadores y conspiradores. Biografias heterodoxas del siglo XIX, Madrid, Espasa Calpe, 17-47, p. 19.

17 LINKER (en prensa).

18 SÖDERQVIST (2003b).

19 BURDIEL (2000), p. 36. 
tos teóricos sobre el género que se supone fueron puestos encima del tapete para montar El médico en la palestra, la posibilidad de asomarse a unos documentos que hablaban del personaje desde puntos de vista insólitos en el panorama historicomédico más tradicional fue el motivo determinante para acudir al género biográfico como manera de poner orden en tanto material y construir un discurso inteligible y explicable en el marco interpretativo en el que nos deseábamos situar, más allá del esquema impuesto por la narración historiográfica hasta ese momento casi unánimemente aceptada.

A lo largo de los más de quinientos folios del prolongado proceso inquisitorial contra Zapata y en los expedientes colaterales sobre la incautación de sus bienes, desfilaban las voces de un sinfín de personajes que hablaban de él: médicos, cirujanos, boticarios, aristócratas, cocheros, cocineras, cortesanas, criadas, estanqueros, guitarristas, actores, etc. Unos y unas eran pacientes o parientes (o ambas cosas a la vez), otros eran acreedores o deudores, colegas o clientes, amigos o enemigos del médico murciano; todos hablaban de Zapata, relataban su escaso o su frecuente trato con él, referían lo que habían oído a otros y otras sobre él, recordaban o fingían recordar familiaridades, antipatías, discusiones, ceremonias, rituales, o discusiones teológicas o médicas en su presencia y, tal vez, eludían todo aquello que no deseaban revelar. Pero también estaba la voz de Zapata, una voz orgullosa y desafiante en sus escritos de defensa, trémula y asustada en sus confesiones arrancadas en la sala del tormento, contradictoria y deliberadamente ambigua en sus respuestas a los muchos testimonios que los inquisidores le iban presentando. La voz de éstos, sin duda, estaba también allí y de manera muy condicionante, puesto que ellos determinaban el ritmo de las comparecencias, las preguntas que había que hacer y, en última instancia, la manera de registrar documentalmente, por escrito, todas esas voces individuales.

Todo ello determinó la elección de una manera de narrar y de una estructura del relato que no orillara la ardua cuestión de la fragmentación y la tendenciosidad de las voces que nos hablaban del sujeto biografiable. Para facilitar la narración biográfica se decidió concentrar todo el aparato crítico en un último capítulo, titulado «Para discutir». Asimismo, se optó por crear una página en Internet para situar fuera del libro la trascripción literal de la documentación inquisitorial, la identificación bibliográfica completa de los libros de la biblioteca personal de Zapata y la relación de ésta con el sistema de citas $\mathrm{y}$ referencias en las obras publicadas que han llegado hasta nosotros ${ }^{20}$. Esta

$20 \mathrm{http} / /$ www.imf.csic.es/Ciencia/paginas/Proyecto_Zapata.htm. Queremos dejar constancia de nuestro agradecimiento a Mercedes Gallego y a Maria Gil, responsables de la elaboración de la página web. 
decisión de escindir la publicación íntegra del material documental inédito en un soporte diferente y diferenciado del libro, así como la escisión del aparato crítico, al margen (en el doble sentido del término) del relato biográfico, obedeció al deseo final de preservar la singularidad de éste, al tiempo que se respetaba escrupulosamente el imprescindible reconocimiento de las deudas intelectuales y materiales de la obra, así como la necesidad de ofrecer las numerosas discusiones a las que podía dar lugar no ya la reconstrucción biográfica, sino sobre todo los numerosos temas y cuestiones que se abordaban, mencionaban o soslayaban en la narración.

Ésta intenta reflejar una mirada poliédrica hacia el personaje, fruto indudablemente de los diferentes sesgos de las voces que hablan desde las fuentes, como antes hemos mencionado. Ésa fue la razón fundamental para adoptar una estructura ideada sobre la figura de un prisma triangular, mediante el cual se propone al lector tres miradas al sujeto desde tres sucesivos puntos de observación que sintetizamos en los títulos de los tres capítulos: marrano, polemista, médico. Cada uno de los Zapatas resultantes se recorre biográficamente, en el más tradicional sentido del término: respetando una narración que discurre cronológicamente, desde el nacimiento hasta la muerte.

Aun sin pretenderlo en sus inicios, El médico en la palestra ha acabado por reflejar una noción de sujeto, como diría Isabel Burdiel, «fragmentada y múltiple, que permite entender las relaciones y contradicciones existentes entre los diversos planos de actuación e identidad que todos tenemos» ${ }^{21}$.

21 Burdiel (2000), p. 43. 